\title{
Renal Evaluation in Common Variable Immunodeficiency
}

\author{
Giovany Gomes Capistrano, ${ }^{1}$ Gdayllon Cavalcante Meneses, ${ }^{2}$ \\ Fernanda Macedo de Oliveira Neves, ${ }^{1}$ Renata de Almeida Leitão, ${ }^{3}$ \\ Alice Maria Costa Martins $\mathbb{D}^{2},{ }^{2}$ and Alexandre Braga Libório $\mathbb{D}^{1,3}$ \\ ${ }^{1}$ Medical Sciences Postgraduate Program, Department of Clinical Medicine, Federal University of Ceará, Fortaleza, CE, Brazil \\ ${ }^{2}$ Department of Clinical and Toxicological Analysis, Faculty of Pharmacy, Federal University of Ceará, Fortaleza, CE, Brazil \\ ${ }^{3}$ Medical Course, Universidade de Fortaleza (UNIFOR), Fortaleza, CE, Brazil
}

Correspondence should be addressed to Alexandre Braga Libório; alexandreliborio@yahoo.com.br

Received 19 June 2017; Revised 21 December 2017; Accepted 8 January 2018; Published 15 March 2018

Academic Editor: Senthamil R. Selvan

Copyright (c) 2018 Giovany Gomes Capistrano et al. This is an open access article distributed under the Creative Commons Attribution License, which permits unrestricted use, distribution, and reproduction in any medium, provided the original work is properly cited.

\begin{abstract}
Introduction. Common variable immunodeficiency (CVID) comprises a heterogeneous group of disorders characterized by impaired antibody production. Kidney involvement in CVID is described in isolated and sporadic case reports. The objective of this study was to study the renal function pattern in CVID patients through glomerular and tubular function tests. Methods. Study of 12 patients with CVID diagnosis and 12 healthy control individuals. Glomerular filtration rate (GFR), fractional excretion of sodium $\left(\mathrm{FE}_{\mathrm{Na}^{+}}\right)$and potassium $\left(\mathrm{FE}_{\mathrm{K}^{+}}\right)$, urinary concentration, and acidification capacity were measured. In addition, microalbuminuria and urinary monocyte chemoattractant protein-1 (MCP-1) were evaluated as markers of selectivity of the glomerular barrier and inflammation, respectively. Results. In relation to glomerular markers, all CVID patients had normal GFR $\left(>90 \mathrm{~mL} / \mathrm{min} / 1.73 \mathrm{~m}^{2}\right)$, and microalbuminuria and urinary MCP-1 levels were also similar to those of controls. Interestingly, CVID patients had reduced urinary concentration capacity, as demonstrated by lower $U / P_{\mathrm{Osm}}$ ratio, when compared to controls. Also, while all control subjects achieved a urinary $\mathrm{pH}$ less than 5.3 , no CVID patients showed a decrease in urinary $\mathrm{pH}$ to such levels in response to acid loading with $\mathrm{CaCl}_{2}$, characterizing impaired urinary acidification capacity. Conclusion. Patients showed a trend towards an elevated prevalence of tubular dysfunction, mainly related to urinary acidification and concentration capacities.
\end{abstract}

\section{Introduction}

Common variable immunodeficiency (CVID) comprises a heterogeneous group of disorders characterized by impaired antibody provision. It is the most frequent symptomatic primary antibody disorder, with a prevalence of approximately $1: 25,000$ to $1: 50,000$ [1]. Clinically, CVID is characterized by susceptibility to recurrent infections and various sequelae and complications, including bronchiectasis, autoimmunity, enteropathy, splenomegaly, granulomatous inflammation, lymphoproliferation, and malignancy [2].

Kidney involvement in CVID has been described only sporadically in isolated case reports. Renal granuloma
[3-5], focal segmental glomerulosclerosis [6], membranoproliferative glomerulonephritis [6], renal amyloidosis [7], and end-stage renal disease have all been described in CVID patients. However, it is not possible to ascertain whether all these kidney-associated clinical manifestations are directly related to CVID or only coincidental associations.

Although the most common renal diseases present with a significant reduction in glomerular filtration rate (GFR), in its acute (generally reversible) or chronic (almost always irreversible) forms, several factors can also affect renal tubular function. Renal tubular acidosis (RTA), nephrogenic diabetes insipidus, and electrolyte abnormalities are clinical entities that can go unnoticed in clinical practice, especially in their 
milder forms. Although overlooked by the attending physician, such disturbances can have short- and long-term complications $[8,9]$.

While GFR is usually calculated in daily medical practice from serum creatinine, tubular function, although altered in interstitial nephropathies such as renal granuloma, is not routinely evaluated. Because CVID has been associated with renal interstitial alterations in several cases [3-5], the objective of the present study was to study the renal function pattern in CVID patients through GFR and tubular function tests. Also, we measured urinary monocyte chemoattractant protein-1 (MCP-1) levels, an emerging biomarker to assess renal inflammatory lesions [10].

\section{Methods}

2.1. Patients. This is a cross-sectional study of 12 patients with CVID diagnosis, undergoing clinical follow-up at Hospital Universitário Walter Cantídio of Universidade Federal do Ceará. The study was carried out from January to July 2014. The diagnosis of CVID was based on the ESID/ Pan-American Group for Immunodeficiency [11] (PAGID) criteria; patients were male or female with a marked decrease in IgG levels ( $\geq 2$ SDs less than the mean for age) and a marked decrease in levels of at least 1 of the isotypes IgM or IgA, while meeting all of the following criteria:

(1) onset of immunodeficiency at age older than 2 years;

(2) absent isohemagglutinins, poor response to vaccines, or both;

(3) exclusion of defined causes of hypogammaglobulinemia.

The patients were undergoing treatment with intravenous immunoglobulin infusion every 4 weeks. The CVID group was compared to a control group that consisted of 12 age- and sex-matched healthy volunteers.

The study protocol was reviewed and approved by the Ethics Committee of Hospital Universitário Walter Cantídio, Federal University of Ceará, in Fortaleza, Brazil. Patients were included in the study only after signing the informed consent form.

2.2. Clinical and Laboratory Parameters. At the medical consultation, signs and symptoms were evaluated, and the following aspects were recorded: age, gender, previous chronic diseases (heart failure, arterial hypertension, diabetes mellitus, cancer, or autoimmune diseases), recurrent urinary tract infection ( $\geq 2$ episodes in six months or $\geq 3$ in one year), time of diagnosis, use of other concomitant drugs, previous infectious complications, and their sequelae. The following laboratory parameters were evaluated: plasma and urine creatinine $\left(P_{\mathrm{Cr}}\right.$ and $\left.U_{\mathrm{Cr}}\right)$, urea $\left(P_{\text {Urea }}\right.$ and $\left.U_{\text {Urea }}\right)$, measured osmolality $\left(P_{\mathrm{Osm}}\right.$ and $\left.U_{\mathrm{Osm}}\right), \mathrm{pH}\left(P_{\mathrm{pH}}\right.$ and $\left.U_{\mathrm{pH}}\right)$, sodium $\left(P_{\mathrm{Na}^{+}}\right.$and $\left.U_{\mathrm{Na}^{+}}\right)$, and potassium $\left(P_{\mathrm{K}^{+}}\right.$and $\left.U_{\mathrm{K}^{+}}\right)$; plasma bicarbonate $\left(P_{\mathrm{Bic}}\right)$; microalbuminuria; and urinary MCP-1.

2.3. Renal Function Evaluation. GFR was estimated using the CKD-EPI formula [12] and was considered abnormal when $\leq 90 \mathrm{~mL} / \mathrm{min} / 1.73 \mathrm{~m}^{2}$. All patients were submitted to a $12-$ hour water and food fasting. Fractional excretion of sodium $\left(\mathrm{FE}_{\mathrm{Na}^{+}}\right)$, potassium $\left(\mathrm{FE}_{\mathrm{K}^{+}}\right)$, and calcium $\left(\mathrm{FE}_{\mathrm{Ca}^{++}}\right.$were calculated by standard formulas. Microalbuminuria was determined by spot collection, and abnormal values were considered if $>30 \mathrm{mg} /$ day. Also, urinary MCP-1, a marker of glomerular inflammation, was measured.

Urinary concentrating capacity was evaluated by the ratio between urinary and plasma osmolality $\left(U / P_{\text {Osm }}\right)$ after a 12 hour water and food fasting. Urinary acidification was evaluated by measuring urinary $\mathrm{pH}\left(U_{\mathrm{pH}}\right)$ at baseline $\left(T_{0}\right)$ and $4 \mathrm{~h}\left(T_{4}\right)$ after ingestion of $\mathrm{CaCl}_{2}, 2 \mathrm{mEq} / \mathrm{kg}$ of body weight [13]. Metabolic acidosis induced by $\mathrm{CaCl}_{2}$ load was documented by a decrease in serum $\mathrm{HCO}_{3}$ - concentrations $>3 \mathrm{mmol} / \mathrm{L}$ and $\mathrm{pH}<7.35$. Failure to decrease urinary $\mathrm{pH}$ $\left(U_{\mathrm{pH}}\right)$ to $<5.3$ after $\mathrm{CaCl}_{2}$ load was considered consistent with some form of distal renal tubular acidosis (RTA) [14]. All tubular function tests were also performed in the control group.

2.4. Analytical Methods. $P_{\mathrm{Cr}}$ and $U_{\mathrm{Cr}}$ were measured by the Jaffe method. $P_{\text {Urea }}$ and $U_{\text {Urea }}$ were measured by UV kinetic method. $P_{\mathrm{Na}^{+}}, U_{\mathrm{Na}^{+}}, P_{\mathrm{K}^{+}}, U_{\mathrm{K}^{+}}, P_{\mathrm{Ca}^{++}}$, and $U_{\mathrm{Ca}^{++}}$were measured by flame photometry. Microalbuminuria was measured by the immunoturbidimetric method (Tinaquant ${ }^{\circledR}$, Roche). $P_{\text {Osm }}$ and $U_{\text {Osm }}$ were assessed by freezingpoint depression. $P_{\mathrm{pH}}$ and $P_{\mathrm{Bic}}$ were determined in a $\mathrm{pH} /$ blood gas system (AVL compact-1, Medical Instruments). $U_{\mathrm{pH}}$ was measured with a $\mathrm{pH}$ meter (Quims Ltda). Urinary MCP-1 was determined by sandwich enzyme-linked immunosorbent assay (ELISA) (Boster Biological Technology, Fremont, CA, USA).

2.5. Statistical Methods. CVID patients were compared with the control group. Fisher's exact test and chi-square test were used to analyze categorical frequencies in the patients' group. Differences between two independent continuous variables were evaluated using Student's $t$-test or Mann-Whitney test, as appropriate. Data were expressed as mean \pm standard error (SE). $p<0.05$ was considered statistically significant. SPSS software for Windows, release 10.0 (SPSS Inc. Chicago, USA) was used in all the analyses.

\section{Results}

3.1. Patients' Characteristics. The study included 12 unrelated adult CVID patients ( 7 men and 5 women; age range, 17 to 57 years; median age, 28 years), followed up at Hospital Universitário Walter Cantídio, Fortaleza, Ceará, Brazil. At the symptom onset, the median age was 16.5 years (range, 2 to 37 years). The symptoms perceived at disease onset were repeated respiratory tract infections $(66.7 \%)$, persistent diarrhea (25\%), and recurrent sinusitis and otitis media (8.3\%). The median age at CVID diagnosis was 20 years (age range, 10 to 56 years) with a median delay of 3 years (ranging from 0 to 37 years). Four patients had splenomegaly. No patient had a diagnosis of autoimmune disease or recurrent urinary tract infection. The median time of disease duration at the time of the study was 10 years (range 1 to 38 years). All 
TABLE 1: Common variable immunodeficiency patient's characteristics.

\begin{tabular}{|c|c|c|c|c|c|c|c|c|c|c|}
\hline Patient & $\begin{array}{c}\text { Age } \\
\text { (y), sex }\end{array}$ & $\begin{array}{c}\text { Time of } \\
\text { disease }(y)\end{array}$ & Splenomegaly & Bronchiectasis & $\begin{array}{c}\text { Persistent } \\
\text { diarrhea }\end{array}$ & $\begin{array}{l}\text { Urine } \\
\mathrm{pH} T_{4}\end{array}$ & $U / P_{\mathrm{Osm}}$ & $\begin{array}{c}\mathrm{GFR} \\
(\mathrm{mL} / \mathrm{min} / \\
\left.1.73 \mathrm{~m}^{2}\right)\end{array}$ & $\begin{array}{l}\text { Albumin } \\
\text { excretion } \\
\text { rate }(\mathrm{mg} / \mathrm{g})\end{array}$ & $\begin{array}{c}\mathrm{MCP}-1 \\
(\mathrm{pg} / \mathrm{mg}-\mathrm{Cr})\end{array}$ \\
\hline 1 & $26, \mathrm{~m}$ & 19 & Yes & Yes & No & 5.65 & 3.2 & 212 & 1.1 & 11.3 \\
\hline 2 & $31, \mathrm{f}$ & 10 & No & Yes & No & 5.39 & 4.1 & 114 & 4.2 & 42.2 \\
\hline 3 & $19, \mathrm{f}$ & 6 & No & Yes & No & 5.32 & 2.5 & 91 & 3.2 & 16.1 \\
\hline 4 & $22, \mathrm{~m}$ & 20 & No & Yes & No & 5.71 & 3.4 & 98 & 3.5 & 12.8 \\
\hline 5 & $31, \mathrm{~m}$ & 19 & No & Yes & No & 5.49 & 2.4 & 96 & 2.6 & 18.3 \\
\hline 6 & $57, \mathrm{f}$ & 28 & No & No & Yes & 5.37 & 2.6 & 93 & 3.5 & 4.7 \\
\hline 7 & $28, \mathrm{~m}$ & 1 & No & Yes & No & 6.21 & 1.1 & 138 & 4.2 & 89.5 \\
\hline 8 & $39, \mathrm{f}$ & 3 & Yes & No & No & 5.43 & 2.3 & 98 & 5.1 & 45.8 \\
\hline 9 & $17, \mathrm{~m}$ & 8 & No & Yes & Yes & 5.75 & 1.4 & 144 & 4.5 & 31.5 \\
\hline 10 & $57, \mathrm{~m}$ & 38 & Yes & Yes & Yes & 5.4 & 2.3 & 129 & 4.4 & 91.7 \\
\hline 11 & $18, \mathrm{f}$ & 3 & Yes & No & Yes & 5.46 & 2.1 & 149 & 16 & 178.9 \\
\hline 12 & $44, \mathrm{~m}$ & 10 & No & No & Yes & 6.3 & 2.4 & 90 & 0.8 & 32.9 \\
\hline
\end{tabular}

patients were undergoing regular immunoglobulin infusions. Complete demographic and clinical data of CVID patients are shown in Table 1.

\subsection{CVID Patients Have Normal Glomerular Filtration} Rate and Selective Barrier. All CVID patients had normal GFR $\left(>90 \mathrm{~mL} / \mathrm{min} / 1.73 \mathrm{~m}^{2}\right)$. The median GFR was $106 \mathrm{~mL} /$ $\mathrm{min} / 1.73 \mathrm{~m}^{2}$ (range $90-212$ ). As a measure of glomerular barrier integrity, urinary albumin excretion rate was measured, and all patients had values within the normal range. Urinary MCP-1 levels (a marker of inflammatory state-see in Discussion) were also measured, and there was a trend towards no difference when CVID patients were compared with controls ( $47.9 \pm 14.5$ versus $42.1 \pm 7.1 \mathrm{pg} / \mathrm{mg}$ creatinine, $p=0.703)$; see Figure 1 .

3.3. CVID Patients Have Selective Tubular Dysfunction. The comparison between the CVID patients and the control group showed no differences in age, gender, and systolic and diastolic blood pressure (Table 2). Urinary concentration capacity defect, as demonstrated by a lower $U / P_{\text {Osm }}$ ratio, was observed when comparing CVID patients with controlsFigure 2. Regarding urinary acidification, while all control subjects achieved a urinary $\mathrm{pH}$ less than 5.3, no CVID patients showed a decrease in urinary $\mathrm{pH}$ to such levels in response to acid loading with $\mathrm{CaCl}_{2}$, characterizing impaired urinary acidification capacity (Figure 3). No patient had baseline serum bicarbonate levels $<22 \mathrm{mEq} / \mathrm{L}$, and thus, a full diagnosis of tubular renal acidosis could not be attained.

Tubular handling of other electrolytes (sodium, potassium, calcium, and chlorine) was also evaluated, but all patients had serum values within normal ranges, and no significant difference in excretion fraction of such electrolytes could be detected in comparison with that of control subjects (see Table 2).

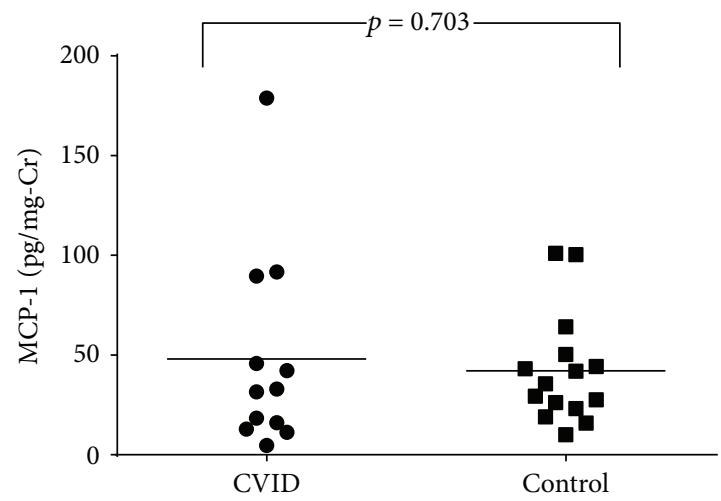

FIgURE 1: Urinary MCP-1 levels in CVID patients and control subjects.

\section{Discussion}

This is the first study that evaluated glomerular and renal tubular function in CVID patients. The main finding of our study is finding that CVID showed a trend towards an association with specific functional renal tubular dysfunctions (e.g., impaired urinary concentration and acidification capacities). In fact, almost all evaluated patients presented both disturbances.

To the best of our knowledge, the only study evaluating renal disorders in CVID, in addition to case reports, is one evaluating glomerular filtration rate only, using serum creatinine-based formulas [15], and, in accordance to our findings, no significant alteration was disclosed in CVID patients regarding glomerular filtration. We expanded glomerular evaluation in such patients by measuring microalbuminuria and urinary MCP- 1 . While microalbuminuria is largely recognized and used in daily practice as an important risk factor in renal damage progression and therapeutic target [16], urinary MCP-1 is emerging as a potential 
TABLE 2: Demographic and clinical data of CVID patients and subjects controls.

\begin{tabular}{|c|c|c|c|}
\hline & CVID patients & Control & $p$ \\
\hline Age (years) & $32.4 \pm 4.1$ & $31.6 \pm 1.8$ & 0.8 \\
\hline GFR $\left(\mathrm{mL} / \mathrm{min} / 1.73 \mathrm{~m}^{2}\right)$ & $121.0 \pm 10.4$ & $112.2 \pm 2.8$ & 0.8 \\
\hline Albumin/creatinine excretion rate $(\mathrm{mg} / \mathrm{g})$ & $4.4 \pm 1.1$ & $3.1 \pm 1.1$ & 0.04 \\
\hline $\mathrm{FE}_{\mathrm{Na}^{+}}(\%)$ & $0.9 \pm 0.5$ & $0.5 \pm 0.1$ & 0.5 \\
\hline $\mathrm{FE}_{\mathrm{K}^{+}}(\%)$ & $7 \pm 3.3$ & $5.6 \pm 0.8$ & 0.2 \\
\hline $\mathrm{FE}_{\mathrm{Ca}^{++}}(\%)$ & $7.9 \pm 0.4$ & $7.4 \pm 0.1$ & 0.1 \\
\hline $\mathrm{FE}_{\mathrm{Cl}^{-}}(\%)$ & $1.5 \pm 7.7$ & $9.0 \pm 0.1$ & 0.4 \\
\hline$U / P_{\text {Osm }}$ & $2.5 \pm 0.2$ & $3.4 \pm 0.1$ & $<0.001$ \\
\hline Urinary MCP-1 (pg/mg-Cr) & $48 \pm 14.5$ & $42.1 \pm 7.1$ & 0.7 \\
\hline
\end{tabular}

FE: fractional excretion.

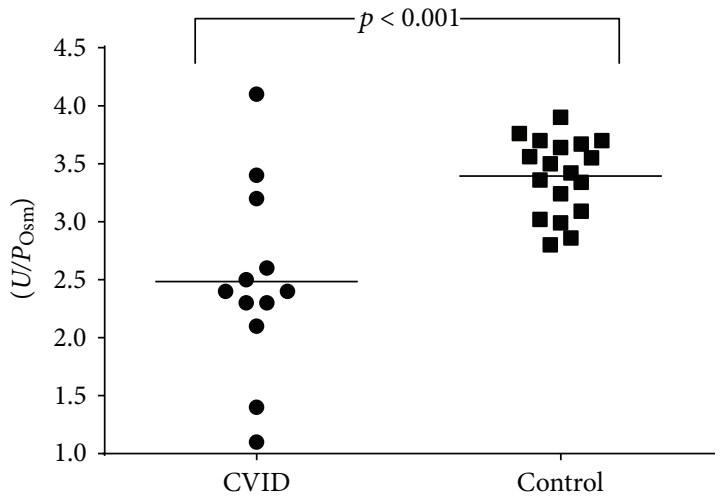

Figure 2: Urine/plasma osmolality $\left(U / P_{\text {Osm }}\right)$ in CVID patients and control subjects.

Urine acidification test

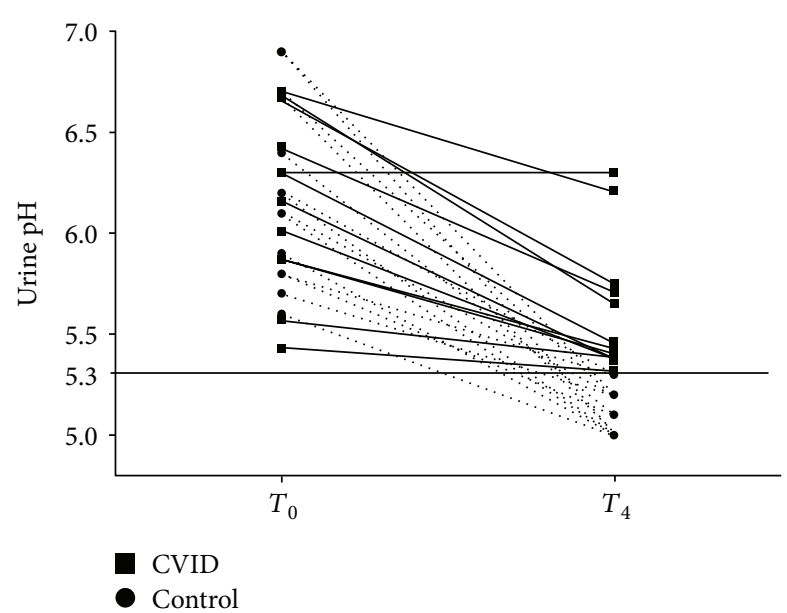

FIgURE 3: Urine $\mathrm{pH}$ before and after acidification test in CVID patients and controls. Urine $\mathrm{pH}$ under 5.3 after test is considered normal.

biomarker to monitor renal inflammation and has also been associated with poor renal prognosis [10].

In our cohort, no CVID patients had glomerular filtration rate alterations or glomerular filtration barrier damage/ inflammation markers. Although we studied a relatively low number of patients, we can suggest that CVID patients are at low risk of developing severe renal impairment in association with glomerular function.

However, when tubular function was assessed, we surprisingly observed a trend towards urinary acidification and concentration capacity impairment. None of the patients were able to show urinary $\mathrm{pH}$ reduction $<5.3$ after oral acid load. To ascertain that the urinary acidification test was performed adequately, all control subjects showed adequate urinary $\mathrm{pH}$ reduction. Because all CVID patients had normal levels of serum bicarbonate at baseline $(>24 \mathrm{mEq} / \mathrm{L})$, we can affirm that these patients had incomplete distal renal tubular acidosis. In incomplete distal RTA, net acid excretion is maintained at a rate equal to acid generation. This is achieved by an increase in ammonium excretion that offsets the reduction in titratable acid excretion caused by the high urine $\mathrm{pH}$ [17]. Thus, patients with this disorder are able to maintain normal serum bicarbonate concentrations. Although CVID patients maintained normal serum bicarbonate levels, early osteoporosis [18] and recurrent renal lithiasis [19] can complicate evolution in patients with incomplete tubular renal acidosis.

The second impaired tubular function observed in CVID patients was the urinary concentration capacity. CVID patients showed lower maximum urinary concentrations after a $12 \mathrm{~h}$ water and food fasting when compared to control subjects. Although we did not measure serum antidiuretic hormone $(\mathrm{ADH})$ levels, CVID patients' failure to achieve high urinary osmolality in comparison with controls after a $12 \mathrm{~h}$ water and food fasting strongly suggests there is an incomplete tubular response to $\mathrm{ADH}$. Although these patients showed normal osmolality values at baseline and had no polyuria complaints, this incapacity to achieve maximum urinary concentration can predispose these patients to hypovolemia and dehydration under stress conditions.

It is a challenge to suggest any mechanisms for these tubular alterations in CVID patients, and, at present, we can only suggest possible pathways. We had previously demonstrated similar alterations in leprosy patients [20]. In leprosy, renal involvement is better described and associated with immune complex deposition. As CVID patients usually have recurrent infections, this could also be a possible explanation. Although we did not have any patients with recurrent 
urinary tract infection, it is possible that incipient interstitial nephropathy was present in these patients. Alternatively, it has been described that CVID patients can develop transient positivity to anti-SSA antibodies due to passive transmission via immunoglobulin infusion [21]. Because distal RTA is a common clinical feature in Sjogren's syndrome [22], it is possible that passive transmission of antibodies, such as anticarbonic anhydrase II antibody, can be related to some aspects of tubular dysfunction in such patients. Our patients did not test positive to routine autoantibody tests; however, we were not able to test them for anticarbonic anhydrase II.

The main limitation of the present study is our inability to progress regarding the pathophysiology of renal tubular disorders disclosed in CVID patients. Studies focusing on direct antibodies against renal tubular components through immunohistochemistry and additional morphological studies from renal biopsies will contribute to our understanding of renal involvement in CVID. Also, we studied a reduced number of patients, and, therefore, it is not possible to obtain definitive results.

In conclusion, we performed the most complete renal evaluation in CVID patients to date. We found no alterations in glomerular function or inflammation. However, we observed a trend towards an elevated prevalence of tubular dysfunction in CVID, mainly related to urinary acidification and concentration capacity alteration.

\section{Disclosure}

The funding sources had no role in the study design, data collection and analysis, decision to publish, or preparation of the manuscript.

\section{Conflicts of Interest}

The authors declare that they have no conflicts of interest.

\section{Acknowledgments}

Alexandre Braga Libório and Alice Maria Costa Martins are recipients of a grant from the Conselho Nacional de Desenvolvimento Científico e Tecnológico (CNPq). Alexandre Braga Libório is a recipient of a grant from the Fundação Cearense de Apoio ao Desenvolvimento Científico e Tecnológico (FUNCAP).

\section{References}

[1] E. S. Resnick, E. L. Moshier, J. H. Godbold, and C. Cunningham-Rundles, "Morbidity and mortality in common variable immune deficiency over 4 decades," Blood, vol. 119, no. 7, pp. 1650-1657, 2012.

[2] B. Gathmann, N. Mahlaoui, L. Gérard et al., "Clinical picture and treatment of 2212 patients with common variable immunodeficiency," Journal of Allergy and Clinical Immunology, vol. 134, no. 1, pp. 116-126.e11, 2014.

[3] F. Fakhouri, C. Robino, M. Lemaire et al., "Granulomatous renal disease in a patient with common variable immunodeficiency," American Journal of Kidney Diseases, vol. 38, no. 2, pp. e7.1-e7.3, 2001.
[4] D. A. Torigian, D. F. LaRosa, A. I. Levinson, L. A. Litzky, and W. T. Miller Jr, "Granulomatous-lymphocytic interstitial lung disease associated with common variable immunodeficiency: CT findings," Journal of Thoracic Imaging, vol. 23, no. 3, pp. 162-169, 2008.

[5] A. Meyer, H. J. Lachmann, A. D. Webster, A. Burns, and $\mathrm{K}$. Thway, "Hypercalcemia in a patient with common variable immunodeficiency and renal granulomas," American Journal of Kidney Diseases, vol. 45, no. 5, pp. e90-e93, 2005.

[6] K. Tsuji, H. A. Uchida, T. Ono et al., "A case of focal segmental glomerulosclerosis in an adult patient with hypogammaglobulinemia superimposed on membranoproliferative glomerulonephritis in childhood," BMC Nephrology, vol. 13, no. 1, p. $46,2012$.

[7] A. K. Kadiroğlu, Y. Yıldırım, Z. Yılmaz et al., "A rare cause of secondary amyloidosis: common variable immunodeficiency disease," Case Reports in Nephrology, vol. 2012, Article ID 860208, 4 pages, 2012.

[8] M. Laroche, J. Cesini, and I. Tack, "Osteoporosis and renal tubular dysfunction," Joint Bone Spine, vol. 79, pp. S96-S98, 2012.

[9] P. Labarga, P. Barreiro, L. Martin-Carbonero et al., "Kidney tubular abnormalities in the absence of impaired glomerular function in HIV patients treated with tenofovir," AIDS, vol. 23, no. 6, pp. 689-696, 2009.

[10] M. J. Kim and F. W. K. Tam, "Urinary monocyte chemoattractant protein-1 in renal disease," Clinica Chimica Acta, vol. 412, no. 23-24, pp. 2022-2030, 2011.

[11] M. E. Conley, L. D. Notarangelo, and A. Etzioni, "Diagnostic criteria for primary immunodeficiencies," Clinical Immunology, vol. 93, no. 3, pp. 190-197, 1999.

[12] A. S. Levey, L. A. Stevens, C. H. Schmid et al., "A new equation to estimate glomerular filtration rate," Annals of Internal Medicine, vol. 150, no. 9, pp. 604-612, 2009.

[13] J. R. Oster, J. L. Hotchkiss, M. Carbon, M. Farmer, and C. A. Vaamonde, "A short duration renal acidification test using calcium chloride,” Nephron, vol. 14, no. 3-4, pp. 281-292, 1975.

[14] V. M. Buckalew, D. K. McCurdy, G. D. Ludwig, L. B. Chaykin, and J. R. Elkinton, "Incomplete renal tubular acidosis. Physiologic studies in three patients with a defect in lowering urine $\mathrm{pH}$," The American Journal of Medicine, vol. 45, no. 1, pp. 32-42, 1968.

[15] A. Gaspar, G. Miranda, E. López, K. Rodríguez, and N. Segura, "Estimation of glomerular filtration rate in adults with common variable immunodeficiency treated with intravenous immunoglobulin. What formula should we use?," Revista Alergia México, vol. 61, no. 2, pp. 45-51, 2014.

[16] G. Cerasola, S. Cottone, and G. Mulè, "The progressive pathway of microalbuminuria: from early marker of renal damage to strong cardiovascular risk predictor," Journal of Hypertension, vol. 28, no. 12, pp. 2357-2369, 2010.

[17] C. Wang and D. K. Beede, "Effects of ammonium chloride and sulfate on acid-base status and calcium metabolism of dry Jersey cows," Journal of Dairy Science, vol. 75, no. 3, pp. 820828, 1992.

[18] M. Weger, H. Deutschmann, W. Weger, P. Kotanko, and F. Skrabal, "Incomplete renal tubular acidosis in 'primary' osteoporosis," Osteoporosis International, vol. 10, no. 4, pp. 325-329, 1999.

[19] S. Arampatzis, B. Röpke-Rieben, K. Lippuner, and B. Hess, "Prevalence and densitometric characteristics of incomplete 
distal renal tubular acidosis in men with recurrent calcium nephrolithiasis," Urological Research, vol. 40, no. 1, pp. 5359, 2012.

[20] R. A. Oliveira, G. B. Silva Jr, C. J. Souza et al., "Evaluation of renal function in leprosy: a study of 59 consecutive patients," Nephrology Dialysis Transplantation, vol. 23, no. 1, pp. 256262, 2008.

[21] R. G. van der Molen, D. Hamann, J. F. M. Jacobs et al., "AntiSSA antibodies are present in immunoglobulin preparations," Transfusion, vol. 55, no. 4, pp. 832-837, 2015.

[22] F. Pessler, H. Emery, L. Dai et al., "The spectrum of renal tubular acidosis in paediatric Sjögren syndrome," Rheumatology, vol. 45, no. 1, pp. 85-91, 2006. 


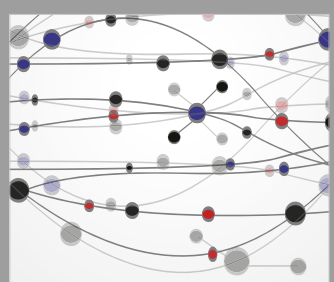

The Scientific World Journal
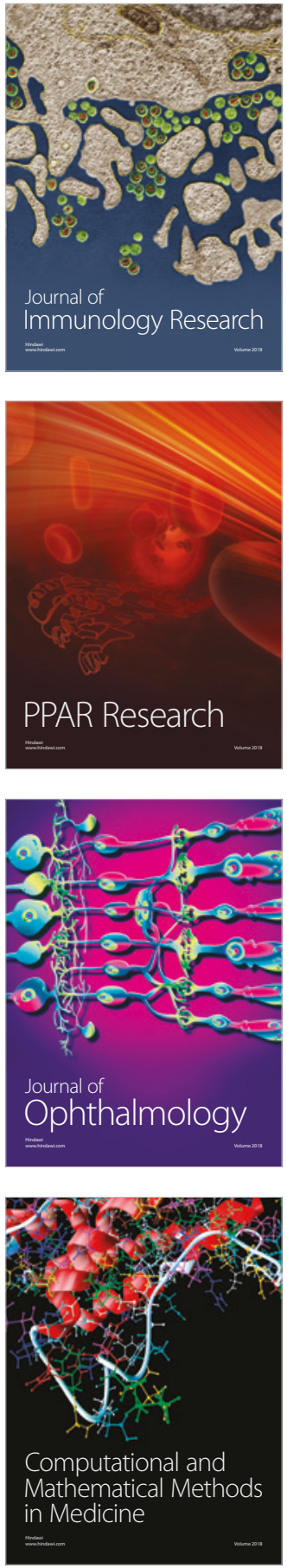

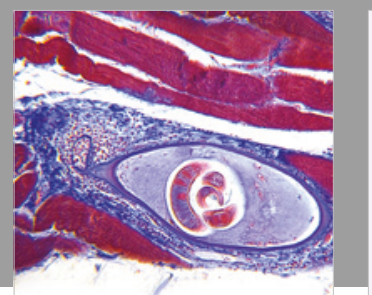

Gastroenterology Research and Practice

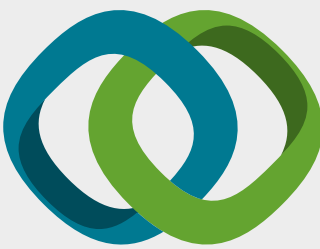

\section{Hindawi}

Submit your manuscripts at

www.hindawi.com
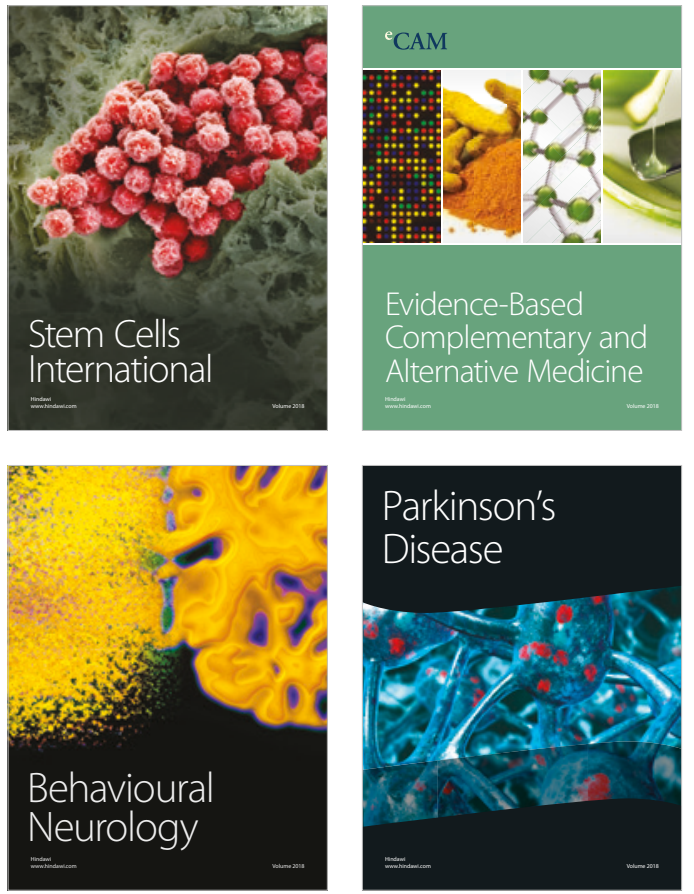

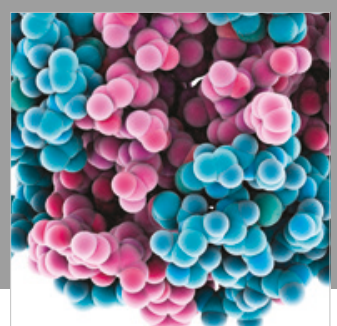

ournal of

Diabetes Research

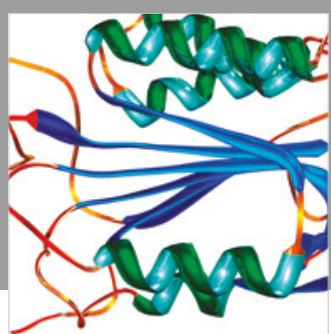

Disease Markers
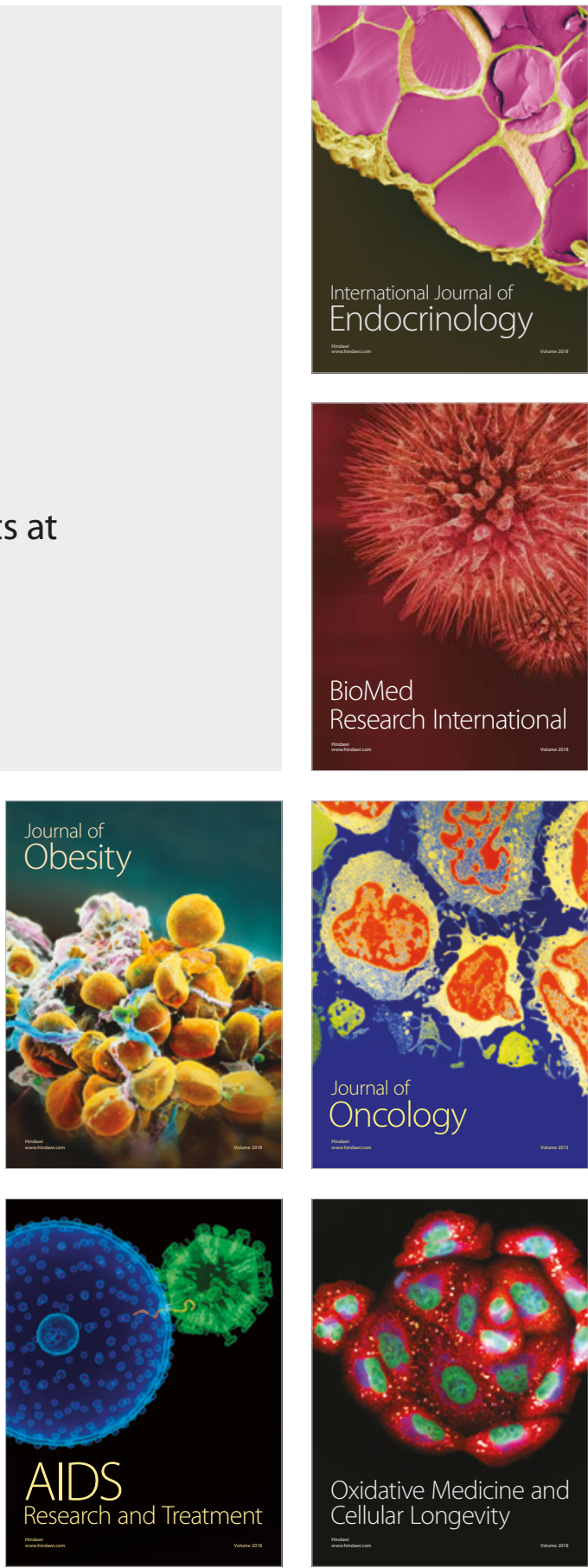